\title{
Comprehensive and Integrated Management Mode for Western Tourist Attractions Based on Low-carbon Eco-tourism
}

\author{
Yuyan Luo ${ }^{1, a}$, Jiaying Chen ${ }^{2, ~}{ }^{\text {, }}$ Jingfei Ren ${ }^{3, b}$, Xiaoling Sun ${ }^{1, c}$ and Chun $\mathrm{Xu}^{1, \mathrm{~d}}$ \\ ${ }^{1}$ College of Management Science, Chengdu University of Technology, Chengdu 610059, China; \\ ${ }^{2}$ College of Business, Sichuan Agricultural University, Chengdu 611830, China \\ ${ }^{3}$ College of Management, Chengdu Information Engineering University, Chengdu 610225, China \\ a luoyuyan13@mail.cdut.edu.cn, *Corresponding author Email: cjy@sicau.edu.cn, \\ brenjingfei@live.cn, c1429301103@qq,com, ${ }^{\mathrm{d}}$ 17781118768@163.com
}

Keywords: Low-carbon eco-tourism, low-carbon tourist areas, comprehensive and integrated management, western tourist attractions.

\begin{abstract}
China's tourism industry has gradually from a period of rapid growth to a period of steady development during the 12th five years, and the mode transformation of tourism economic development would put forward higher requirements towards the management mode and level of tourist attractions. Towards low-carbon economy, low-carbon eco-tourism will become a new way to be sustainable development of tourism industry. In response to the worldwide energy conservation measures, taking into account the theme of economic development and environmental protection, to develop low-carbon eco-tourism is the key point to increase economic power and solve environmental problems in western China. Based on reviewing researches on low carbon and eco-tourism, this paper describes the need for western area to develop low-carbon eco-tourism, and under the guidance of theories, such as complexity science, systems engineering, tourism management and so on, by using of low-carbon integrated technologies, such as STSNMT, RFID, etc. and low-carbon management concepts, the comprehensive and integrated management mode of western tourist areas on the basis of low-carbon eco-tourism is built to provide reference for strategic transition of tourism industry development.
\end{abstract}

\section{Introduction}

Famous international think tank, the club of Rome, said: "the economy and ecology are in an integral entirety, and it is impossible to have benefits and wealth in a world of ecological destruction" ${ }^{[1]}$. With the rapid development of social economy and the rapid increase of population, the issue of climate change is becoming more and more serious, and the global warming is caused by melting glaciers, rising sea levels, climate disasters and a series of adverse consequences serious being harmful to the human survival environment and health and safety. In response to global climate change, with a low carbon economy as the leading factor of low energy consumption, low pollution, low emission and the sustainable growth pattern of high performance, high efficiency and high benefit is gradually accepted by the social from all walks of life.

Under the leadership of the development trend of low carbon economy, the sustainable development of various industries is the trend of low carbon direction. There is no doubt that in this context, to go the way of the sustainable and healthy development of tourism in our country, we should carry out low carbon economy concept, adopt new growth model, improve energy efficiency and reduce pollution emissions, and change the traditional extensive mode into the emerging intensive way. In view of this, scenic spot in the west with important location is rich in tourism resources, but its construction of infrastructure is weak, ecological environment is fragile and the task of environmental protection is big and in the process of developing western scenic area, to advocate low carbon ecological tourism, to practice low carbon and environmental protection by means of low carbon low carbon integration technology and low carbon management way can help to realize the 
scenic spot of the integrated omni-directional informationization management, in order to protect the fragile natural ecological environment, and this is a very important realistic meaning and approach value.

\section{Research Progress of Low Carbon Ecological Tourism and the Practice}

\subsection{Eco-tourism}

Eco-tourism is the result of the 1980s' concept, the world conservation union (I-UCN) special adviser Ceballos Lascurain first proposed it in $1983^{[2]}$. At that time, this term was not used extensively, some scholars also used the natural tourism, ecological tourism and green tourism to express ${ }^{[3-4]}$. According to the definition of the first world congress on "tourism and the environment" (1992), eco-tourism is the natural tourism that with the view to appreciate and study the natural landscape, wild animals and plants and relevant characteristic culture, and through the way of raising money for nature reserve, creating employment opportunities for local residents and providing environmental education for social public to be help for the natural conservation ${ }^{[5]}$. Later, Mark B Orams $(1995)^{[6]}$, Regina Scheyvens (1999) ${ }^{[7]}$, Chris Ryan, Karen Hughes and Sharon Chirgwin (2000) ${ }^{[8]}$, did research on the aspects of protecting natural environment, ecological tourism management strategy and impact of community ecological tourism and so no.

With the deterioration of environment in our country, ecological damage problems in tourism development is more and more evident. Many scholars pay close attention to ecological tourism, and then start researching. He Jiali (2005) $)^{[9]}$, Zhang jie, Xu bo, etc. $(2005)^{[10]}$, Zhao Yanli and Yang Xuejun (2009) ${ }^{[11]}$, Zheng Yan and Li Qinglei (2011) ${ }^{[12]}$, Ma Junliang (2012 $)^{[13]}$, He Fangyong $(2015)^{[14]}$, Zhao Yan $(2016)^{[15]}$, discussed on the western ecological environment construction, eco-tourism development, environmental issue of eco-tourism, and ecological tourism development mode respectively.

\subsection{Low-carbon Tourism}

Low carbon tourism development started relatively early abroad. The world wild fund for nature - the UK Business and consumer or ganizations (WWF - UK Business and Consumption Unit, 2002) advocated a kind of holiday carbon footprint tools, which provided more useful tools and strategies for sustainable development, under the background of "responsible tourism"[16], it reflected the ideology of low-carbon tourism to a certain extent. Susanne Beckena, David Simmonsb with Chris Frampton (2003) ${ }^{[17]}$, Paul Peeters with Ghislain Dubois $(2009)^{[18]}$, Nae - Wen Kuo and Pei - Hun Chen (2009) ${ }^{[19]}$ have also made certain researches on low-carbon tourism, which mainly contain the relationship between tourism industry energy consumption with tourist behavior, global carbon reduction scheme, quantitative research on energy use of tourism industry and greenhouse gas emission, etc.

As low carbon tourism develops worldwide, it is also gradually becoming popular in China at the same time. Xiao Ge $(2008)^{[20]}$, Liu Xiao (2009) ${ }^{[21]}$, Cai Meng and Wang Yuming (2010) ${ }^{[22]}$, Wang Mou (2012) $)^{[23]}$, Ma Yong and Yang Yang $(2015)^{[24]}$ respectively studied the low carbon tourism behavior, tourists personal carbon footprint and low carbon tourism behavioral intention, the requests that low carbon tourism made to tourism planning and tourists, the main implementation path of low carbon tourism and the development mode of low carbon, etc.

Scholars at home and abroad lacked making the organic integration and contact on the low carbon tourism and ecological tourism. with the coming and developing of the era of low carbon economy, this paper argues that low carbon ecological tourism should combine the two core idea with energy conservation and emissions reduction and activities based on the nature, it should not only embodies the protection of the natural landscape development, but also reflect measures taken to reduce carbon emissions for the climate warming. Under the background of low-carbon economy, in order to develop low carbon ecological tourism, we should use the concept of low carbon economy, in the process of development and utilization of natural landscape, advocating using new type of ways of low energy consumption, low pollution and new management philosophy. 


\section{The Necessity of Developing Low Carbon Ecological Environment of Western Scenic Areas in China}

\subsection{The Key Way of Enhancing the Economic Power of West China}

The western region of our country's tourism resources are incomparable and unique. It is vast and also across multiple latitude. and its topography is complex, rivers and lakes are diverse, and alternating with plateaus, hills, deserts and grasslands, the biological resources are abundant and the natural landscapes are unique. With vast land and diverse nationalities, the western provinces are the most populated areas of minorities in china. In the long-term historical development, it has given birth to the splendid culture and the numerous regional, diverse and original ecological folk customs of ethnic minorities. For many years, the development of original ecological tourism, whose main aspect is natural landscape, has played a decisive role in the economic development of the western region. Compared with the eastern region, firstly, the economic and social development in western China is relatively backward. What's more, the industrial structure remains to be further adjusted and perfected.

Besides, the economic development of ethnic minority areas is related to the strategy of national economic development and security and the unity and stability of the Chinese nation, and it has extremely important strategic significance for the sustainable development of our country's economy. Especially, the ecological environment is an important resource and wealth,and it can accelerate or slow economic development. Experience over a long period of accumulation and practice shows that the formation of some western scenic area tourist resources has experienced a long period of geological evolution, it is irreversible and irreplaceable. The ecological environment is fragile, if broken, it will be difficult to restore, and conversely, it will restrict the development of economy, widen the economic differences between regions and affect the survival of mankind. Therefore, the development of western economy cannot rely on the large-scale industrialized construction. The only method is using low carbon ecological tourism way, that tourism industry continues to play an important part in economy, provides an effective way for to promote the structure adjustment in tourism industry and its upstream and downstream industries, speeds up regional economic development and enhances the development of the western region.

\subsection{The Best Way to Solve the Ecological Environment Problem of Scenic Areas in West China} As the birthplace of human life, western china is the water catchment area of the Yangtze river and Yellow River, its ecological environment protection status plays a crucial role in ecological security pattern, water resources, atmospheric environment around the world and the survival of the human race. At the same time, in the process of ecological civilization construction, "return To Innocence, advocate nature" has become a new fashion. People in the pursuit of material life, meanwhile, paying more and more attention to mental enjoyment, they are more willing to be close to nature, appreciate nature and enjoy nature.

Scenic area of west China is one of the most important tourists travel place of the world, the rapid increase of tourists has already exceeded the capacity of the scenic area, therefore, the western area's carbon emissions increased violently, the environment polluted seriously, and much attention has been paid to ecological environment problems, especially in some areas lack of long-term tourism planning, tourism develops disordered, management mode and technology are backward, making originally fragile ecological environment "worse". So, developing low-carbon ecological tourism, adopting the advanced low carbon technologies, and using the low carbon way of management into six aspects of tourism "food, accommodation, transportation, traveling, shopping, entertainment", and so on, to realize integrated omni-directional informationization management in the scenic area, to drive the upstream and downstream industries involved in tourism scenic area, scenic area management unit, travel agencies, tourist hotels, tourism transportation companies and so on, and to guide tourists to have a responsible tourism, and realizing the low carbon is the best way to solve the problem of ecological environment of the western scenic area. 


\subsection{The Development Adapted to the Low Carbon Economy}

Since the the UN climate change conference was held in 1995, China has always proactively fulfill the mission reduction commitments. "Twelfth five-year" project takes the economic structural strategic adjustment as the main direction. At this stage, our country should not only tamp more solid material civilization and spiritual civilization for the modernization construction, but also make a breakthrough on construction of ecological civilization. To have energy conservation and emissions reduction, building a resource-conserving and environment-friendly modern ecological civilization is the responsibility of the government, enterprises, and also the citizen's morality and obligation. Tourism has become an important way of life for our citizens since entered the well-off society, tourism industry shows its industrial characteristics of low resources consumption, great driving coefficient, plenty of employment opportunities, good comprehensive benefit more and more. So developing the low carbon ecological tourism clearly reflects the energy conservation and emissions reduction measure, and it not only has its own source of power in a new way, but promote the development of other related industries. This is also a wise decision after the Mexico Cancun climate conference in 2010 that the western scenic area response to the measures of energy conservation and emission reduction worldwide.

\subsection{Give Consideration to the Western Economic Development and Environmental Protection}

The scenic area of west China is not only a beautiful scenic tourist area, but also a protective barrier of our country's ecological balance. It not only undertakes the responsibility of developing tourism industry to promote economic development of western region, but also plays the role of becoming the ecological barrier of Chinese nation. These two functions are vital to the west and the country's overall development in China, however, they are also contradictory, if the tourism resources development is disordered and the management methods are traditional, it is easy to increase carbon emissions and other pollutants, causing damage to the ecological environment, then, ecological environment destruction will necessarily restrict the development of tourism economy in the west and forms a vicious circle. If taking the afforestation to have over-protection, it will hurt the more and more vigorous public travel demands and restrict the development of the western tourism economy. The contradiction is particularly acute in some famous ecological fragile western area. As a result, neither sacrifice the ecological environment for economic development, or abandon economic development in order to protect the ecological environment, in front of the two major choices, we must study the path, technology and management mode of the both relative balance development. So to develop low carbon ecological tourism is a win-win situation for developing tourism economy while protecting the natural ecological environment in scenic area of west China.

\section{Theoretical Basis and Technical Support of the Comprehensive Integration Management Mode in Western Scenic Areas}

\subsection{Theoretical Basis}

The comprehensive integrated management for the western scenic area involved in all aspects such as economy, society and ecological environment. According to the characteristics of the western area and the internal and external development situation, the construction of its management mode mainly uses complexity science, the management entropy, managerial dissipative structure, management systems and control, and system engineering theory and so on, as integrated theoretical guidance, as shown in Fig. 1.

\section{(1) Complexity science}

Western scenic area is an open complex giant system, which not only includes the scenic tourist activities and tourism resources interaction, but contains the relationship between human activities and ecological environment, and includes the interaction of various factors in the western area at the same time. According to the study of Mr Qian (1990), complexity is the dynamic characteristics of the open complex giant system ${ }^{[25]}$, so the mechanism between influencing factors of western scenic area are nonlinear, they have complexity characteristics. As a result, to have comprehensive 
integrated management for western area must be clear with the complexity relationship between internal factors.

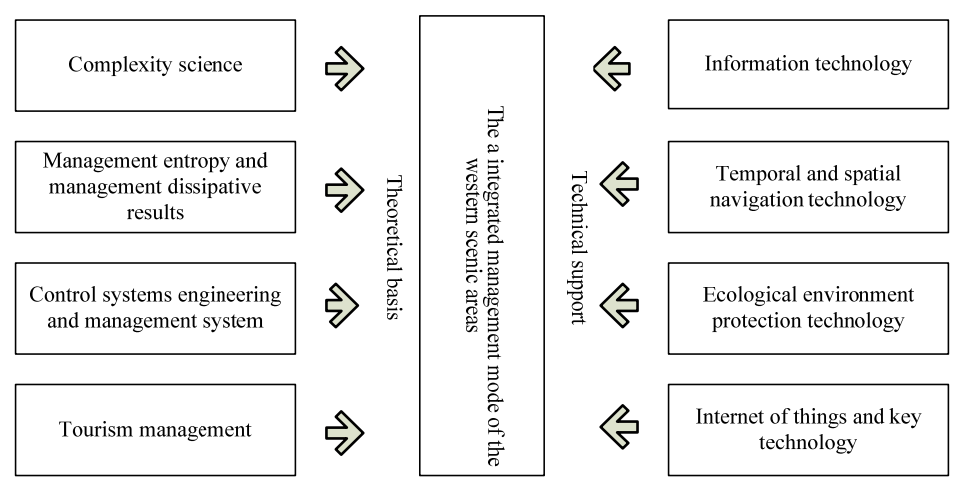

Fig. 1 Main theoretical basis and technical support for comprehensive and integrated management mode of tourist attractions

(2) Management entropy and management dissipative structure.

As an organization, The complexity of the relationship between the western scenic area's own structure and movement and the environment, make its relatively closed organization movement and evolution process full of uncertainty and chaos, thus resulting in the organization system's effective energy decreases and invalid energy increase. It develops from order to disorder and shows a trend of decrease in management performance, which is the management entropy theory reveals. At the same time, the managerial dissipative structure also points out that the organization exchanges substance, energy and information through the external environment, introduce negative entropy flow, making it develops from disorder to order, from lower order to higher order ${ }^{[26]}$, as a result, through the specific technology and management innovation, to promote the scenic area to form the ordered, self-organizing and self-adapting systems, thus leads to improvements of the management performance of the scenic areas.

(3) Systems engineering and management system control

Comprehensive integrated management of the scenic area is a system engineering, from the perspective of system engineering, the comprehensive integrated management of the scenic areas should consider many factors, such as tourism planning, ecological environment, tourist behavior, service and industry management, etc. So it should follow the principles of Integrity, scientificity, relevance and so on. According to the theory of modern management control system theory, management control needs to play the functional role of management. In the control of the western scenic area system, it must be based on studying the probable controlled way and controlled behavior, uses the comprehensive integrated management mode, and combines with advanced information and management technology, to make it in harmony with the western area, the ecological environment and tourists, etc.

(4) Tourism management

Tourism management is the combination of tourism, management, marketing and other interdisciplinary comprehensive science, it not only contributes to tourism landscape planning of the scenic area, tourism enterprise operation and service management, and the formation of industrial integration, etc, but also helps scenic tourists to understand the ecological, economic and social impact of tourism activities, set up the low carbon ecological tourism consciousness, guide their behavior and promote to form the low-carbon consumption behavior habits, to lay a strong foundation on building low carbon ecological tourism of scenic areas and its implementation.

\subsection{Technical Support}

At the part of construction, design and implementation of the comprehensive integrated management mode in the scenic area, the integration of information technology, space-time distribution and navigation technology, monitoring and protecting ecological environment technology, and 
networking technology play an important role in the process of the low carbon management, it relates to whether put the low-carbon ecological tourism into practice really in western scenic area and whether the comprehensive integrated management model is practical and effective or not, as shown in Fig. 1.

(1) Information technology

The current information technology mainly include global positioning system (GPS), remote sensing(RS), geographic information system(GIS), information and communication technologies (ICTS), the 3S technology-the integration of the former three and the $3 \mathrm{G}$ technology-the third generation mobile communication technology, and organically integrates these technologies, then applies them into the tourism industry, through the positioning system and service platform to realize the remote monitoring of scenic attractions and provides information technology support for managing scenic transportation, vehicle scheduling, tourism and scenic spot service, thus to further promote the order and efficient management of scenic area system.

(2) Temporal and spatial navigation technology

temporal and spatial navigation technology is aimed at solving the problem of the balance of passenger flow in scenic spot, in accordance with the data of historical distribution of passenger flow and the data information of tourists' recently visited the scenic spots arrival time, leaving time, waiting time, to predict the future distribution of tourists, to further create a visitor's scheduling strategy, thus to realize real-time scheduling of tourists in the scenic areas, in order to achieve the load balance ${ }^{[27]}$. From the technical level, the way of diversion and comprehensive traffic engineering technology greatly reduces the destruction that the rapid increasing of passenger in hot spots has done to ecological environment.

(3) Ecological environment monitoring and protection technology

Ecological environment monitoring takes use of the principle and technology of physics, chemistry and ecology, it not only monitor the scenic spot' atmosphere, such as carbon emissions, air quality, the degree of soil erosion, river health, more importantly, from the time and space to monitor the destruction and the influence of tourist activities done to the scenic spots inside and around, to provide decision basis of protection for the ecological environment and strategy making, to control carbon emissions of the scenic spot dynamically, and to ensure that it is within the scope of bearing capacity of ecological environment in scenic areas.

(4) Internet of things and key technology

LOT (Internet of Things) is connecting all items with the Internet through information sensing devices, such as RFID, infrared sensors, global positioning system (GPS), laser scanner, to realize intelligent identification, location, tracking, monitoring, management and so on ${ }^{[28]}$. Premier Wen Giabao in the capital technology published titled "to lead China's sustainable development of science and technology" pointed out that we should strive to make breakthrough in key technologies of sensor network and the Internet of things, making information network industry as the "engine" to promote industrial upgrading and move towards the information society.

With the development and maturity of Internet of things and its key technology like RFID, sensor, nanometer, smart insert's developing, the scenic area must gradually apply advanced technology to provide modern convenience for the operation of integrated management mode and the realization of the low-carbon ecological scenic area, in the future of the development of tourism industry.

\section{Comprehensive Integrated Management Mode in Western Scenic Areas 5.1 Emerging Management Mode}

How to utilize the low carbon ecological tourism, achieving economic development and environmental protection on the technology and the application layer is must to be discussed and solved.

Under the condition of the current unit carbon productivity, the expansion of tourism economy and the increase of visitors have a direct impact on the carbon emission and the ecological environment, and then have a direct impact on the sustainable development of scenic areas, as shown in Fig. 2. 


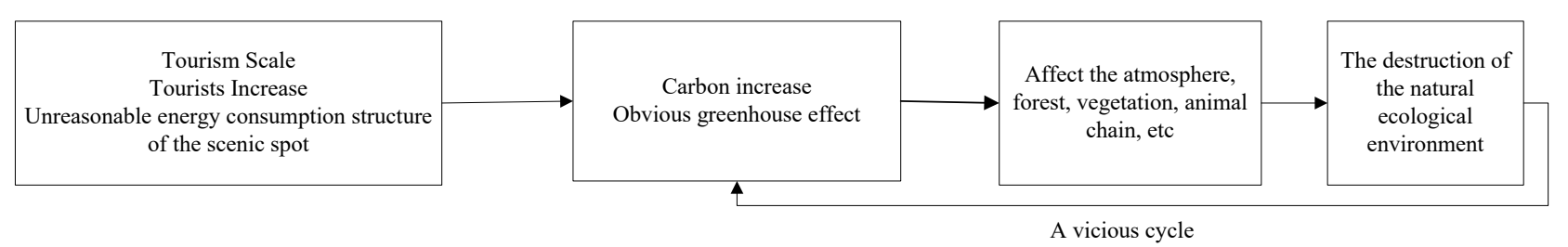

Fig. 2 Movement mechanism and relationship between carbon environment and ecological environment of tourist attractions

In order to solve the vicious cycle of the carbon and ecological environment, and take account of both economic development and ecological protection, this paper proposes a comprehensive integrated management mode which is conducive to the development of tourism and its related industry and the sustainable development of ecological environment of low carbon scenic area, it aims at exploring a kind of integrated management theory and technical methods through low carbon environmental protection, information monitoring and such interdisciplinary subjects, and to reduce carbon emissions and enhance ability of carbon sequestration in many aspects of scenic areas, forming a low-carbon scenic area, solving the contradiction between economic development and ecological protection, to form the management mode of promoting the harmonious coexistence and sustainable development of regional economy, society and environment system.

\subsection{Principles of Management Mode Construction}

Based on the complexity science, system engineering, and tourism management theory, under the low carbon ecological tourism, the comprehensive integrated management model of low carbon scenic area includes the management thought, management theory, the structure of the management system and the integration of management technology and method to achieve the organic connection of low-carbon scenic area.

Through the integration of information technology, temporal and spatial navigation management technology, ecological environment monitoring and protection technology, Internet of things, and system innovation, in the process of exploitation and utilization of scenic area and tourism economic development, monitoring and controlling the increase of management entropy value in complex giant system of the scenic area look forwards the decrease on management entropy or increase on negative entropy value of the complex giant system, the controlled degree of system movement is more orderly, and forms the management dissipative structure of the controlled and orderly movement, realizes the tourists' environmental friendly behavior, and their tracks can be managed. It greatly saves energy and reduces consumption, reduces carbon emissions, thus improves the unit carbon productivity, protects and expands the area of forest at the same time, and enhances the ability of carbon sequestration, so as to achieve economical tourism and the sustainable development of natural ecological environment, the movement mechanism and logic relations as shown in Fig. 3. The movement mechanism and logical relationship of the scenic area management, carbon emissions and ecological environment protection, as shown in Fig. 4.

\subsection{The Comprehensive Integrated Management Mode of Scenic Areas}

Under the low carbon ecological tourism, west scenic area's comprehensive integrated management mode mainly set the management information technique such as the information technology of 3S, $3 \mathrm{G}$ and the RFID (Radio Frequency Identification), STSNMT (Spatial-temporal Spliting Navigation Management Technology), and the monitoring and protection of the ecological environment as technical support, and is constructed through the integration of the ecological environment monitoring system, time and space shunt navigation management system, service management system, industry management system, as shown in Fig. 5.

(1) Ecological environment monitoring system

Ecological environment monitoring system is composed of the environment monitoring subsystem and environmental protection subsystem. Through applying the ecological environmental 
monitoring technology, to have a systematic measurement and observation on the structure and function of the ecosystem of scenic area in time and space, namely, monitoring the carbon emissions, atmosphere, eco-geology, vegetation, water resources and so on in real time, and measuring the ecocide and impact caused by tourists, managers of scenic area, stakeholders of related industries, and the results are used to evaluate and predict the impact of human activities on the ecological system. Monitoring the ecological environment development of scenic area in west China such as Jiuzhaigou, Huanglong, Mount Siguniang, Mount Emei, Mount Qingcheng, Hailuogou Valley, Shangri-La, Mont enneigé Yulong, etc, to find the resources carrying capacity, ecological environment capacity and its evolvement rule, carbon emission and carbon sink development law, as well as providing decision basis for improving the structure of the resources consumption of scenic areas and protecting the natural ecological environment.

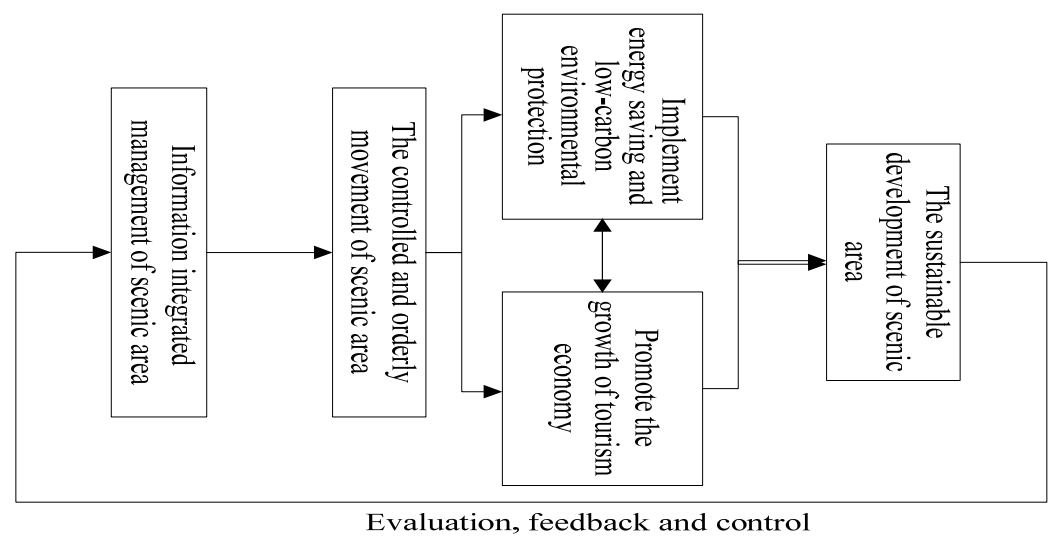

Fig. 3 Logical relationship between movement mechanism and target implementation of comprehensive and integrated management mode in low-carbon tourist attractions

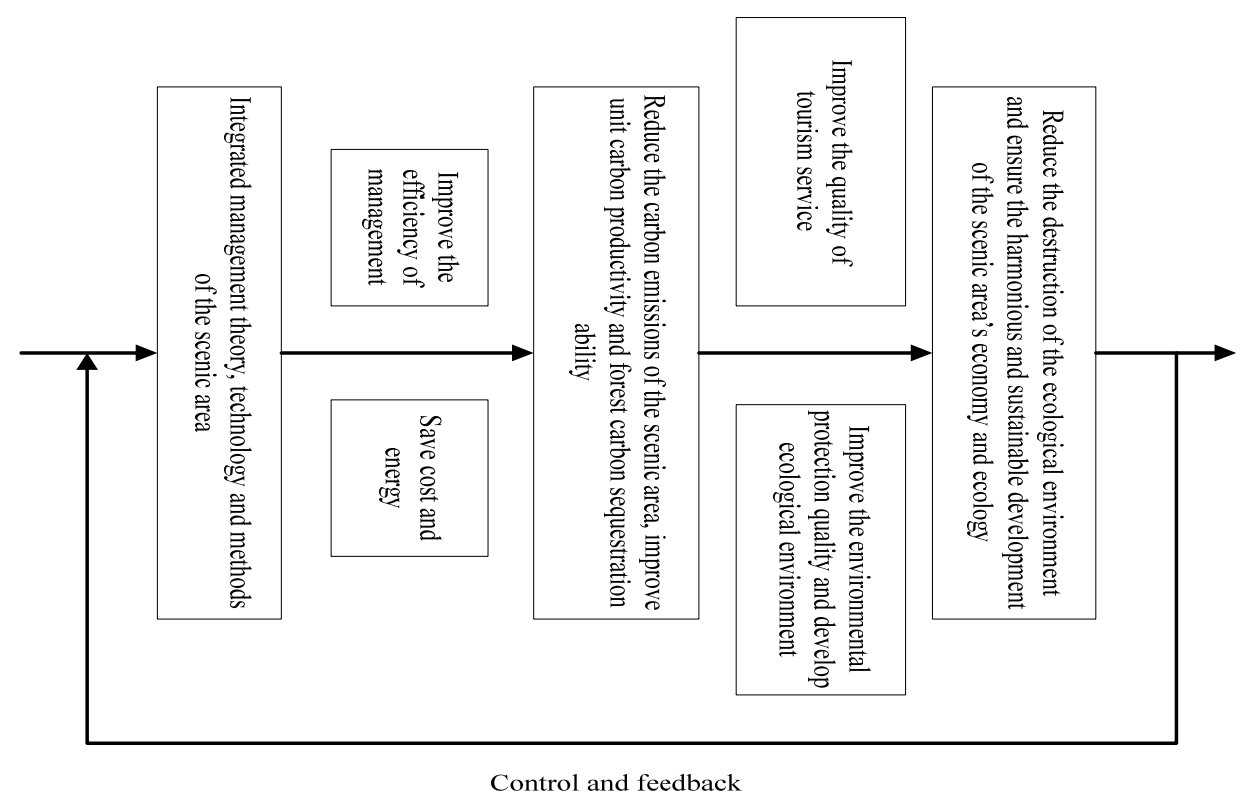

Fig. 4 Movement mechanism and logical relationship among management, carbon emissions and ecological environment protection of tourist attractions 


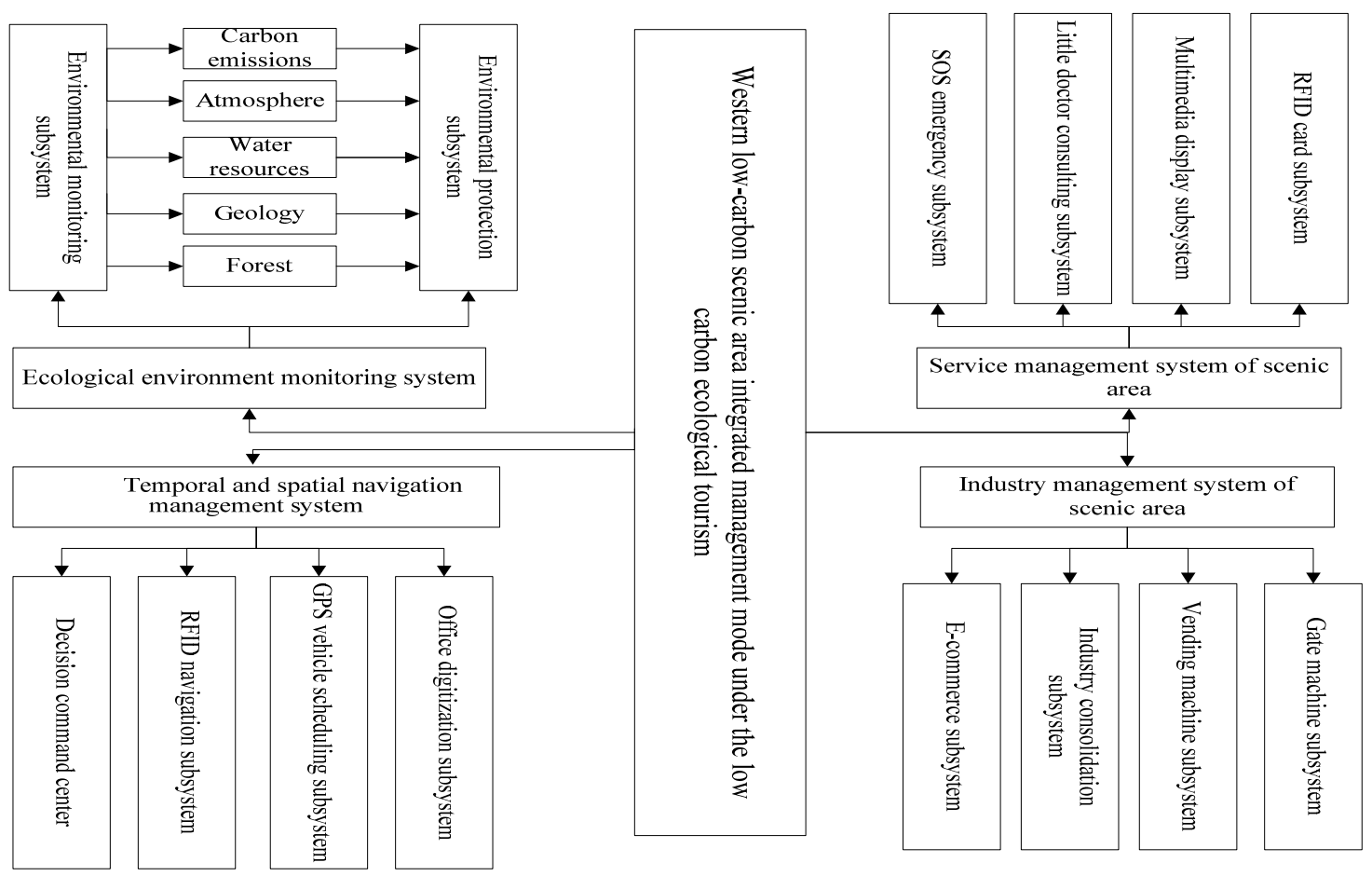

Fig.5 Comprehensive and integrated management mode for western tourist attractions based on low-carbon eco-tourism

(2) Temporal and spatial navigation management system

Temporal and spatial navigation management system consists of decision command center, RFID navigation subsystem, GPS vehicle scheduling subsystem, digital office subsystem and so on. It aims at monitoring and solving the contradiction between the jam in scenic areas in peak tourist seasons and the rising damage of eco-environment. In theory, according to the theory that when the space in relative statics and the time in relative dynamics, the same space is filled with foot passenger distribution in different time. And under the certain spatial-temporal condition of the scenic area and its cluster and the monitoring of information technology, through the mathematical reasoning, several optimized tour route are designed, using time moving to form relatively "empty" space, to make a strategic decision, plan, schedule and shunt navigate on relative uniform distribution and orderly movement of tourists and scenic area vehicles, through effectively guiding, monitoring, and scientific managing a large number of tourists, the scenic transportation is more ordered, vehicle running is more efficient, energy is saved, emissions is decreased, and the flow of energy, material and information between the management organization, tourists and the environment is promoted and strengthened, continuing to introduce negative entropy to "time-space shunt" navigation management system, to make it reach and keep away from balance and highly ordered state ${ }^{[29]}$, in this way, scenic area system will remain high ordered state, carbon dioxide emissions will decrease, and the tourism economy will be harmony with and the natural ecological environment in western scenic area.

(3) Scenic spot service management system

The service management system in scenic area includes the SOS emergency subsystem, little doctor consulting subsystem, multimedia display subsystem, RFID card subsystem and so on. It mainly advocates the low carbon service concept, guides tourists to participate in low carbon environment-protection tourism, and provides visitors with a series of convenient service. It contains the urgent and ordered response and handling for tourists and other safety accidents in the scenic area, through the RFID card subsystem to record and trace the visitors tracks, collecting the density of tourists in an area of the scenic area and providing a reliable information support for the space-time distribution navigation management. And with the low-carbon service method, to make breakthrough on the navigation model of traditional narrative form or personnel description, and to offer professional consultation and guided multimedia display for tourists. 
(4) Industry management system of scenic area

The industry management system of scenic area is composed of the E-commerce subsystem, industry consolidation subsystem, vending machine subsystem, gate machine subsystem and the other components of the system, it uses low carbon management mode, low carbon technology to manage the scenic area resources, and leads the development of the upstream and downstream industries, finally, forms a new mechanism for the protection of the resources in west scenic area and the harmonious development of tourist exploitation, involving the use of the industry management subsystem and gate machine subsystem to changes its traditional extensive static artificial management to elaborate and dynamic smart management, the management cost is reduced. By integrating the E-commerce subsystem and industry consolidation subsystem and gathering industry management, tourism resource information and distribution channel in the same platform, to synthesize and promote many kinds of management information, unified schedule various resources and construct the "one-stop" service to satisfy tourists' different demands, to realize low-carbon industry management in the west scenic area.

\section{Conclusions}

The advent of the era of low carbon economy leads to the new changes of tourism development mode and the transformation of tourism industry. Due to the rapid development of western tourism industry and the increasingly sharp contradiction with natural ecological environment, the development of the scenic west inevitably will be move towards a low carbon road with its own characteristics. Face to the low carbon ecological tourism in the western scenic area, the smooth implementation of integrated management mode is a complicated system engineering, so there is still a long way to go. So in the process of practicing low carbon concept, tourists behavior should be guided constantly with low carbon marketing concept, and optimal control of the western scenic area management mode should be carried with low carbon technology, to realize the wisdom management for western scenic area through the use of low carbon management, ultimately, to achieve the harmonious and sustainable development between tourism economy and the ecological environment system in western scenic area.

\section{Acknowledgments}

This work was supported by the National Natural Science Foundation of China (Grant no. 71501019, 71501138, 71601164 and 71371130), Youth Program of Social Science Research of Sichuan Province for the Twelfth Five-year Plan (Grant no. SC15C005 and SC15C030), General Program of Education Department in Sichuan Province (Grant no. 16SB0071 and 16SB0049), General Program of Mineral Resources Research Center in Sichuan Province (Grant no. SCKCZY2014-YB04).

\section{References}

[1] X. S. Xu, The economic mode of sustainable development construction based on ecological economy, Journal of Anhui Agricultural Sciences, 34. 6 (2006) 1219-1223.

[2] H. Ceballos-Lascuráin, The future of ecotourism, Mexico Journal, 1 (1987) 13-14.

[3] D. A. Fennell, P. F. J Eagles, Ecotourism in Costa Rica: a conceptual framework, Journal of Park \& Recreation Administration, 6.3 (1990) 23-34.

[4] M. Miller The rise of costal and marine tourism, Ocean \& Costal Management, 20. 3 (1993) 181-199.

[5] Editorial committee of China 21th century agenda. China 21th century agenda, Environmental Science Press, Beijing, 1994, pp. 124-127.

[6] M. B. Orams, Towards a more desirable form of ecotourism, Tourism Management, 16. 1 (1995) 3-8. 
[7] R. Scheyvens. Ecotourism and the empowerment of local communities, Tourism Management, 20. 2 (1999) 245-249.

[8] C. Ryan, K. Hughes, S. Chirgwin, The gaze, spectacle and ecotourism, Annals of Tourism Research, 27.1 (2000) 148-163.

[9] J. L. He, Discussion on three problems related to ecological environment construction, Ecological Economy, 8 (2005) 32-36.

[10] J. Zhang, B. Xu, M.Z. Huang. Problems and countermeasures existing in Chinese nature reserve developing ecological tourism, China's Forestry Enterprise, 70 (2005) 19-22.

[11] Y. L. Zhang, X. J. Yang, H. P. Si, Discussion on main environmental problems and solutions in ecological tourism, Environmental Protection and Recycling Economy, 7 (2009) 50-54.

[12] Y. Zheng, Q. L. Li, National park: a new idea of eco-tourism development in Western China, Reformation \& Strategy, 27.7 (2011) 111-114.

[13] J. L. Ma. Ecological tourism development in the Western region from the perspective of circular economy, Academic Exploration, 5 (2012) 81-83.

[14] F. Y. He. Evaluation of the ecoturism development potential for provinces in western China, Journal of Arid Land Resources and Environment, 29.4 (2015) 189-194.

[15] Y. Zhao. Research on development and production of grassland eco-tourism resourches in Western Sichuan minority areas, Chinese Journal of Agricultural R esources and Regional Planning, 37. 1 (2016) 227-230.

[16] H. Wang, L. Song, L. L. Gou, The application and discussion of low-carbon tourism in developing island tourism - a case study of island tourism in Dalian, Marine Development and Management, 27.5 (2010) 75-79.

[17] S. Becken, D. G. Simmons, C. Frampton, Energy use associated with different travel choices, Tourism Management, 24.3 (2003) 267-277.

[18] P. Peeters, G. Dubois, Tourism travel under climate change mitigation constraints, Journal of Transport Geography, 18.3 (2010) 447-457.

[19] N. W. Kuo, P. H. Chen, Quantifying energy use, carbon dioxide emission, and other environmental loads from island tourism based on a life cycle assessment approach, Journal of Cleaner Production, 17. 15 (2009) 1324-1330.

[20] G. Xiao, Advocacy of low-carbon tourism means, Zhejiang tourism on innovation and development, (2008).

[21] X. Liu. Low-carbon economy and low-carbon tourism, China Collective Economy, 5 (2009) 154-155.

[22] M. Cai, Y. M. Wang. Low-carbon tourism: a new way of tourism development, Tourism Tribune, 25.1 (2010) 13-17.

[23] M. Wang. Exploring the concept of low carbon tourism and implementation approaches, China Population, Resources and Environment, 22.8 (2012) 166-171.

[24] Y. Ma, Y. Yang. Explanation on value of low-carbon tourism and reconstruction of development model, Ecological Economy, 31.3 (2015) 122-125.

[25] X. S. Qian, J. Y. Yu, R. W. Dai. A new field of science - open and complex system and methodology, Nature Magazine, 1 (1990) 4-10.

[26] P. Y. Ren, J. X. Fan, L. Huang, B. Zhang, New mode and its performance evaluation of Chinese governance structure mode: taking Sinohydro Group as a case, China Industrial Economy, 7 (2005) 97-104.

[27] Y. Q. Qiu, P. Ge, P. Y. Ren, A study on temporal and spatial navigation based on the load-balance of tourists in Jiuzhaigou Valley, Resources Science, 32.1 (2010) 118-123.

[28] B. Y. Wang. Review on internet of things, Journal of Electronic Measurement and Instrument, 23. 12 (2009) 1-7.

[29] G. Feng, P. Y. Ren, P. Ge, Z. Z. Zhu, J. H. Ran, A study of the navigation management mode for spatial-temporal separation of tourists in Jiuzhaigou national park during rush hours based on management entropy theory and RFID technology, Tourism Science, 24 . 2 (2010) 8-15. 